This is an Accepted Manuscript of an article published by Taylor \& Francis in Knowledge Management Research \& Practice on 9 November 2020, available online: http://www.tandfonline.com/10.1080/14778238.2020.1838962 


\title{
The Role of Organization Structure in the Success of Start-Up Science and Technology Parks (STPs)
}

\author{
Al-kfairy, M. and Mellor, R.B.* \\ Computing and Maths, Kingston University, London. UK \\ * Corresponding author on r.mellor@kingston.ac.uk
}

\begin{abstract}
Early stage start-up STPs, have a central initiative controlling the decisionmaking. In early maturity, better decision-making is required and decisions are best taken with the input of optimally two on-cluster firms; this ambidextrous situation is superior under all circumstances. Where poor-fit innovations abound and where the STP has been unable to attract large firms, retaining a hierarchical decision process is most helpful, even when the quality of decisionmaking is poor. This developmental trajectory will lead to market failure as size, and the seriousness of the concomitant potential losses, increases.
\end{abstract}

With time, off-cluster firms move outward, inhabiting a band 4-7 km from the STP; their size remains modest and their innovation output is low. On-cluster firms are resilient to externalities; their innovation output is large and strongly correlated with social/networking expenditure.

These new results are reviewed here as a contribution towards a "road map" to help STP decision-making and regional policy.

Keywords: Science and Technology Parks, Innovation Management, Innovation Network, Business Clusters Organisation.

\section{Introduction}

Tech Entrepreneurship is the cornerstone of a developed nation's wealth (Porter, 1990), and one prominent tool in the tech entrepreneurial ecosystem is the Science and Technology Park (STP). STPs are often founded in order to enhance regional development by supporting 
networking between firms, creating incubation programmes and promoting knowledge spillovers from e.g. universities (IASP, 2020). Typically, it is envisaged that STPs and other business clusters deliver essential benefits for the firms inhabiting the organisation, as well as for the surrounding region (Maskell, 2001; Sureephong et al., 2007; McCann \& Folta, 2011). Young clusters can be large, depending on the amount of investment (private or public) and the approach employed;top-down or bottom-up (Skokan et al., 2012). In such top-down cases, managers face a set of immediate problems, including how to collect sufficient rent to survive (see Gower et al 1994, Gower et al, 1996). One could imagine that to generate additional income; client firms are rapidly recruited and that they furthermore may well be active in various fields, so, as Bathelt et al. (2004) point out, it is difficult to imagine how synergy ("local buzz") can be constructed if the themes present in the STP are unrelated. Indeed it is known (Johnston \& Huggins, 2018) that in bottom-up STPs, on-cluster firms select new working partners from various sources like firms or HEIs, according to narrow speciality (for recent reviews see also Ng et al., 2019, Lecluyse et al., 2019, as well as Hobbs et al., 2017).

There are more than 365 STPs in Europe, employing around 750,000 people and having a total investment of $€ 12$ billion (Rowe, 2014). STPs help firms produce more innovation by encouraging networking and knowledge sharing. STPs can be erected by local or central authorities (a "top down" approach), and have a mixed success rate and in these instances the central management instance (the "Cluster Initiative" or "CI") may become more occupied with maintaining basic income generation for the STP structure, than in promoting technological progress. Conversely "bottom-up" clusters can develop from a "buzz-driven" adhocracy (similar to the Nonaka concept of "ba", for a view of this in an STP context, see Hansson, 2007) through various stages, to become specialised and successful STPs, although the survival rate is low: Worldwide, STP performance is disappointing; for 
some examples see e.g. Wadhwa (2013), Kelly \& Firestone (2016) and Pugh et al. (2018). The pooled success rate for "top-down" and "bottom-up" initiatives is around $\sim 20 \%$ (Kelly and Firestone, 2016). This emphasises the need for new concepts and approaches.

The first new and important concept arises from the ideas of Nobel laureate Stiglitz, who pointed out that it is the corporate architecture that determines the performance of an organization (see e.g. Stiglitz \& Greenwald, 2014). This concept is highly relevant to the organisational structure of STPs and indeed this opens the area of knowledge management generally (see e.g. Mellor 2014a, Mellor 2018), and STP performance in particular (Al-kfairy et al, 2019b) to econometric analysis. To avoid hyperbole, there is no reason to expect that one size fits all, or that the same solutions are optimal for all stages of STP development and indeed for all of the regions of the world. Nonetheless, a mathematical approach allows quantitive investigations to be performed concerning the role of organizational architecture on the knowledge sharing, innovation and, ultimately, the successful performance (or not) of STPs.

The second important new concept is that innovations may be negative: What may be apparently an attractive innovation beforehand may indeed turn out afterwards to be a poor fit. As Mellor (2019) points out, the costs associated with implementing an innovation detract from the financial success of a beneficial innovation, but those same costs add extra losses to the losses caused by adopting an inappropriate innovation. Thus, adopting a "poor" innovation incurs higher costs than the benefit accrued by adopting a similar "good" innovation. Will et al (2019) modelled this situation for organizations, finding that more levels of management hierarchy in firms in environments with a surfeit of poor-fit innovations is beneficial, simply because rejecting innovations, even at random, reduces the number of poor innovations accepted, thus saving money. By definition STPs inhabit (and should indeed be completely immersed in) a high-innovation environment. Thus choosing 
"good" over "bad" innovations is essential for them because wrong choices will inevitably accumulate and lead to market failure in the medium term (Mellor, 2020).

\section{Results}

\section{Start-up structure:}

Results emphasise the importance of the organisational structure in an STP, which in turn is based on several factors, including; the stage of STP development (age), the size of the cluster, the composition of the on-cluster firms, the experience and quality of decisionmaking by managers and the type of innovation. All of these are essential factors in selecting the best STP structure at any one time (Albahari et al, 2018). Al-kfairy et al (2019a) pointed out that in the very early stages of STP formation; a structure called "Star Topology" was most efficient, where all firms co-inhabiting an STP were connected to the CI by one gatekeeper in each firm and communicated together via the CI. The major benefit of this structure is that when the STP is small and both experience and resources amongst all oncluster actors are scarce, that the "star" is very efficient in terms of minimizing transaction costs.

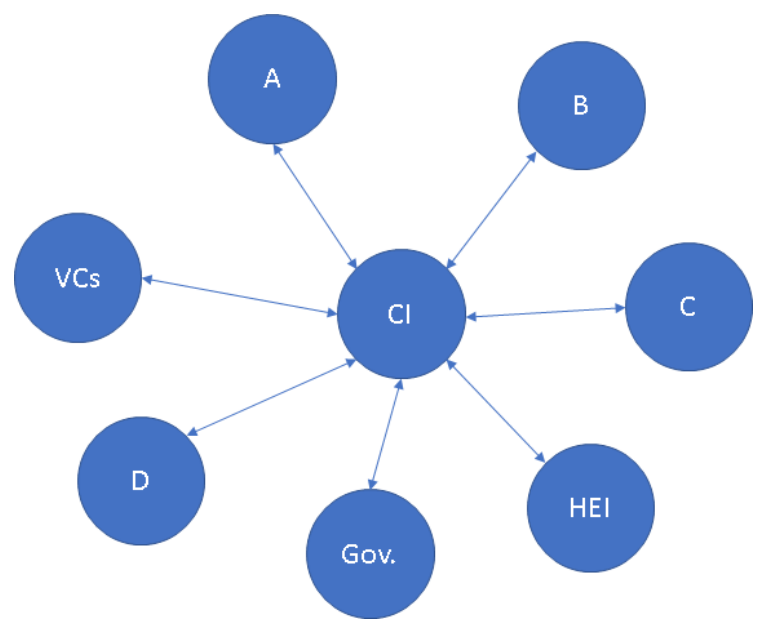

Figure 1. Illustrating the Star Mode, where CI = Cluster Initiative, VCs = Venture Capital, Gov $=$ Government and HEI = Higher Education Institution (from Al-kfairy et al, 2019a). 
Figure 1 shows hypothetical connections to government, assuming some form of state support for the nascent organization (Sternberg, 2014). In this scenario state support of some kind is nominally taken into account because of the concept of "debt": The CI is not a production unit and therefore to operate it creates "debt", which must be covered by some mechanism, either subscription or lease of premises to inhabitants, or by support from the state (local or central government) or some mixture of these sources. Figure 1 also shows a connection to HEI, which donates a university or similar Higher Education Institute (see Díez-Vial \& Montoro-Sánchez, 2016 and also Bencke et al, 2019). In this latter regard it is interesting that Johnson (Johnson 2019; Johnson 2020) shows that prior links (see later; "knowledge network") are the most important factor in establishing contact with HEIs, as well as the relatively narrow specificity of the knowledge involved.

There are other connections possible; the obvious one describes the relationship between CI and the other CIs of other STPs. Rowe (2014) reported that there are more than 365 STPs in Europe and again the most efficient structure is a star topology through sectoral associations e.g. UKSPA (in the UK) and the International Association of Science Parks and Areas of Innovation (IASP). These associations will mainly adopt the topology associated with low transaction costs.

\section{STP growth and decision-making:}

In the early start-up stages of STP development the potential gains and losses are relatively modest, and this holds even under conditions of poor management (Mellor, 2016). As shown in Figure 1, it is most beneficial to have a central Cluster Initiative (CI) controlling the decision-making process at this early stage because despite adopting "negative innovations", both gains and losses are manageable. A "negative" could be choosing a poor-fit firm to join the STP. This is regarded as a "negative innovation" because, from the Innovation Based 
View (Mellor, 2015a), potential or on-cluster inhabitants of the STP can be referred to as "innovation" because this view regards the innovative new firm as a mere business vehicle containing the innovation.

However, approaching the early maturity stage and with a commitment to a highgrowth trajectory, a higher quality of decision-making is required. The CI is the executive instance that manages the STP (it may even manage the physical estate) in a way that helps on-cluster firms to grow e.g. providing sets of activities, support policies and selecting new inhabitants. The CI thus acts as events organizer but probably lacks the in-depth sectorspecific insight that may be needed to select inhabitants for a specialized STP active in e.g. nanotechnology.

Figure 2 shows that as the STP grows and the CI continues to be the decision-making instance, then the size of the financial consequences grow too. By making decisions randomly the STP will be economically placed between $2.3 \times 10^{4}$ monetary units in positive and $4.6 \times 10^{4}$ monetary units in debt, with a median of $0.6 \times 10^{4}$ in debt. Further explanations to the origin of this figure are given in the appendix.

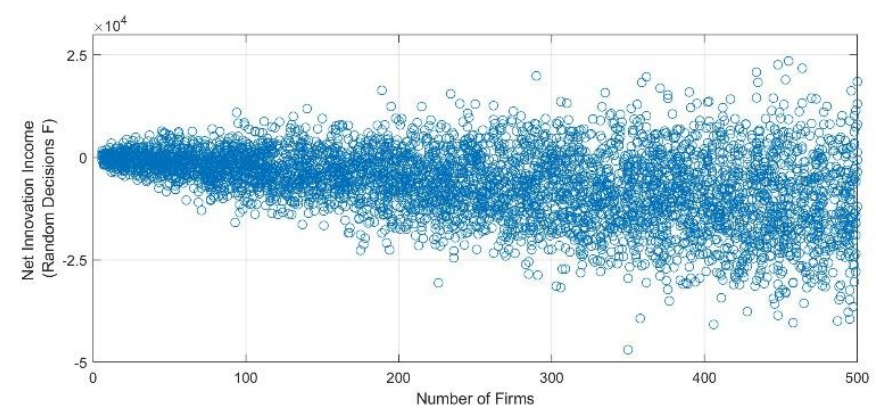

Figure 2. Outcomes in monetary units for CI-only decision-making (originally fig 5 in Alkfairy et al 2020)

Al-kfairy et al (2020) also modelled the situation where the CI can form a stronger structure together with on-cluster firms, including involving them in decision-making. The results (figure 3) show that worst-case situation is $8.0 \times 10^{4}$ monetary units in debt (this is 
because of the extra transaction costs incurred), but despite the extra transaction costs incurred, best-case profits can extend to $5.4 \times 10^{4}$ monetary units. Further explanations to the origin of this figure are given in the appendix.

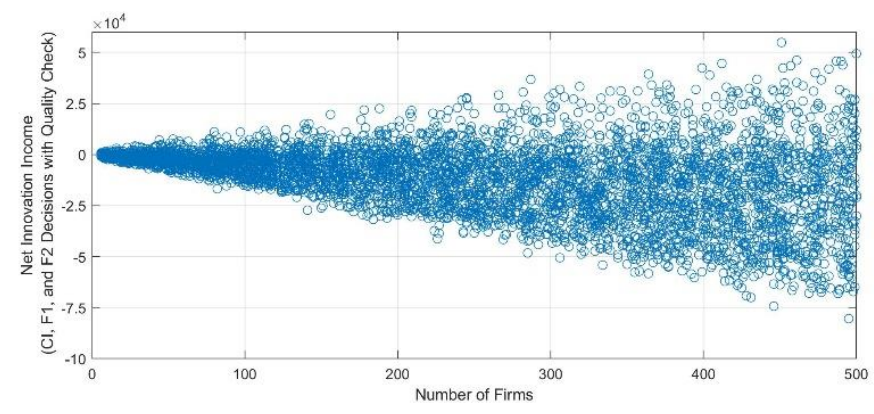

Figure 3. Outcomes in monetary units for ambidextrous decision-making between $\mathrm{CI}$ and on-cluster firms. (originally fig 9 in Al-kfairy et al 2020)

The success scenario found by Al-kfairy et al (2020) is that the young STP must attract lively, inventive young firms and thus form an innovation environment that is attractive to larger and more established firms. These larger firms may wish to enter the STP to get new ideas, or to headhunt innovative staff away from start-ups, or even to better acquire start-ups directly by e.g. buying shares or even takeovers. For whatever reason, the CI should involve these larger firms in decisions about selecting new inhabitants because these larger firms possess deep and sector-specific insights. Obviously there may eventually be several larger firms on-cluster, but the modelling shows that the CI should involve only 2 at any one time (Al-kfairy et al 2020) because involving more serves to greatly increase transaction costs while adding only marginally to the quality of decisions. This ambidextrous situation is superior under all circumstances of middle-phase growth.

Later, when knowledge is well established, each on-cluster firm can form its semiindependent networking organisation structure, perhaps even without involving the CI, bringing the maximum of knowledge benefit for all those embedded in the STP ecosystem (Al-kfairy et al 2020). 
Conversely, in environments with a surfeit of poor-fit innovations and where the middle-phase STP has been unable to attract large firms on-cluster, then retaining a hierarchical (CI only) decision-making process is most helpful (after all, an STP is rarely democratic), and this is the best case even when the quality of decision-making amongst CI managers is poor. This is because even by random chance (e.g. flipping a coin), expensive mistakes will be avoided half the time (Al-kfairy et al 2020, Will et al, 2019). Nevertheless, either the STP will probably remain small, or will grow only slowly until such time when a poor decision is made that has large consequences and thus forces bankruptcy on the organization (Mellor, 2020).

\section{Benefits for on-cluster firms:}

Several previous studies focussed on the role of STPs in enhancing the development of firms inhabiting the STP by measuring the financial growth of on- and off-cluster firms (e.g. DiezVial \& Fernández-Olmos, 2017). Generally authors show that on-cluster firms are more innovation-driven than off-cluster firms (see Al-kfairy et al., 2018, Guadix et al., 2016; Vásquez-Urriago et al., 2016). On-cluster firms are more insulated from negative externalities of the economy, and (in the IT branch), are larger than off-cluster firms, being around av. 130 employees as compared to av. 70 employees for off-cluster. Al-kfairy et al (2019b) used a panel data approach to investigate factors influencing the growth of on-cluster firms using off-cluster firms as a control group. Size and age were found to influence turnover, as did the ability to innovate, but whereas size and age had a quadratic (non-linear) impact on financial growth, innovation capabilities have a positive linear impact. Employment correlates mainly to age, previous years' innovation and shareholder investment. Innovation output, (the ratio of patents asset value to turnover) was correlated to networking measured as social expenditure, which in turn exhibits a positive influence on innovation capabilities. 


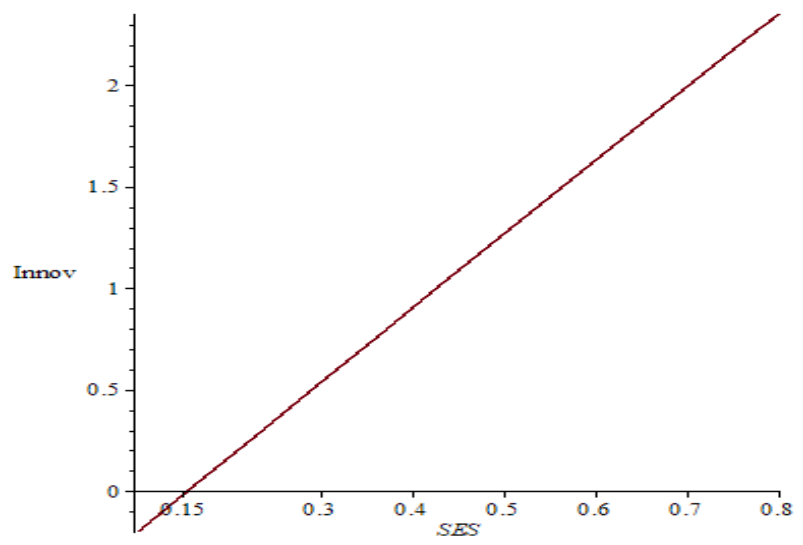

Figure 4. The relationship between networking spend and innovation level (originally fig 6 in Al-kfairy et al 2019b, Showing that in order to successfully provoke innovation, on-cluster firms need to spend more than $15 \%$ of their turnover on organizing social events, networking, partnership with other firms etc)

Using longitudinal studies of a mature STP (Mjärdevi Science Park, Linköping, Sweden), Al-kfairy et al (2018) reported that entrants could be micro-firms, often with one or zero employees (we speculate that the individuals involved had kept their "day job") and that these either grow or - if not - disappear after 4-5 years. On-cluster firms grow to around seventeen years old and to size one hundred and fifty to two hundred employees, then level out as growth stops. One hypothesis could be that at this stage, owners either decide on a strategy of 'capped growth' (Mellor, 2014a) staying within the cluster, but other interpretations are also possible, for example that while some on-cluster firms mature and plateaux-out, others that are more successful may simply leave the cluster (Mellor, 2020) for a multitude of reasons e.g. heading for an IPO, or requiring larger physical quarters, etc.

For off-cluster firms, there was a negligible correlation between the effects of $R \& D$, shareholders investments or social networking on firms' innovation and employment or financial growth (Al-kfairy et al, 2019b). 


\section{The knowledge network:}

Earlier results from modelling single organizations show that innovations accrued through networks are almost as valuable as "home grown" innovations (Mellor, 2015b). This confirms earlier conclusions that it is the most important factor for sustaining innovation in an STP, because it represents a good way for knowledge spill-over to occur both vertically and horizontally by intra-firm networking as well as between firms (see Casanueva et al., 2013). Computer models have shown the value of "just-in-time" knowledge acquired by networking (see Mellor, 2014a; Mellor, 2014b) and, although it is acknowledged that this is probably not a universal measure of innovation output (see e.g. Mellor, 2019 and Delgado el al., 2010), the results presented by Al-kfairy et al (2020) certainly seem to continue to support this hypothesis and indicate that it can profitably be applied to STPs.

\section{Regional and geographical aspects:}

One point of controversy, as outlined by Henriques et al (2018), concerns the co-location of those firms regarded as being on-cluster: Charlot et al (2015) states “... economic development patterns are characterised by strong spatial concentration at the regional level ... distance and geography do matter in a global world. ... This basically consists of the Marshallian idea of agglomeration economies related to knowledge diffusion" and more recently Rodríguez-Pose \& Comptour (2012) have considered spatial co-locating to be very important; "importance of proximity for the transmission of economically productive knowledge, as spill overs are affected by strong distance decay effects." (Rodríguez-Pose \& Comptour $(2008, \mathrm{p} 37)$ and "Physical proximity is often regarded as the key aspect making some regions genuine loci of innovation. The basic reasoning is that innovation travels with difficulty, and suffers from strong distance decay effects" (Rodríguez-Pose \& Comptour, 2012, p280). 
To contribute to this debate Kussainov et al (2020) took four UK STPs with clear and specialised industry profiles consisting of one of modest size and another of medium size active mostly in computing \& IT, as well as a second pair of STPs one of modest size and another of medium size, active mostly in biotech/medical sectors, and determined the spatial distribution of off-cluster firms in the same industry sectors, as defined by SIC (Standard Industrial Classification) codes, around the STP up to a distance of $10 \mathrm{~km}$. The distribution of off-cluster firms sharing the SIC codes as on-cluster firms were mashed onto a map of the UK and ArcGIS was used to establish zones around each STP. Firms with general services SIC codes were also included, as a control experiment.

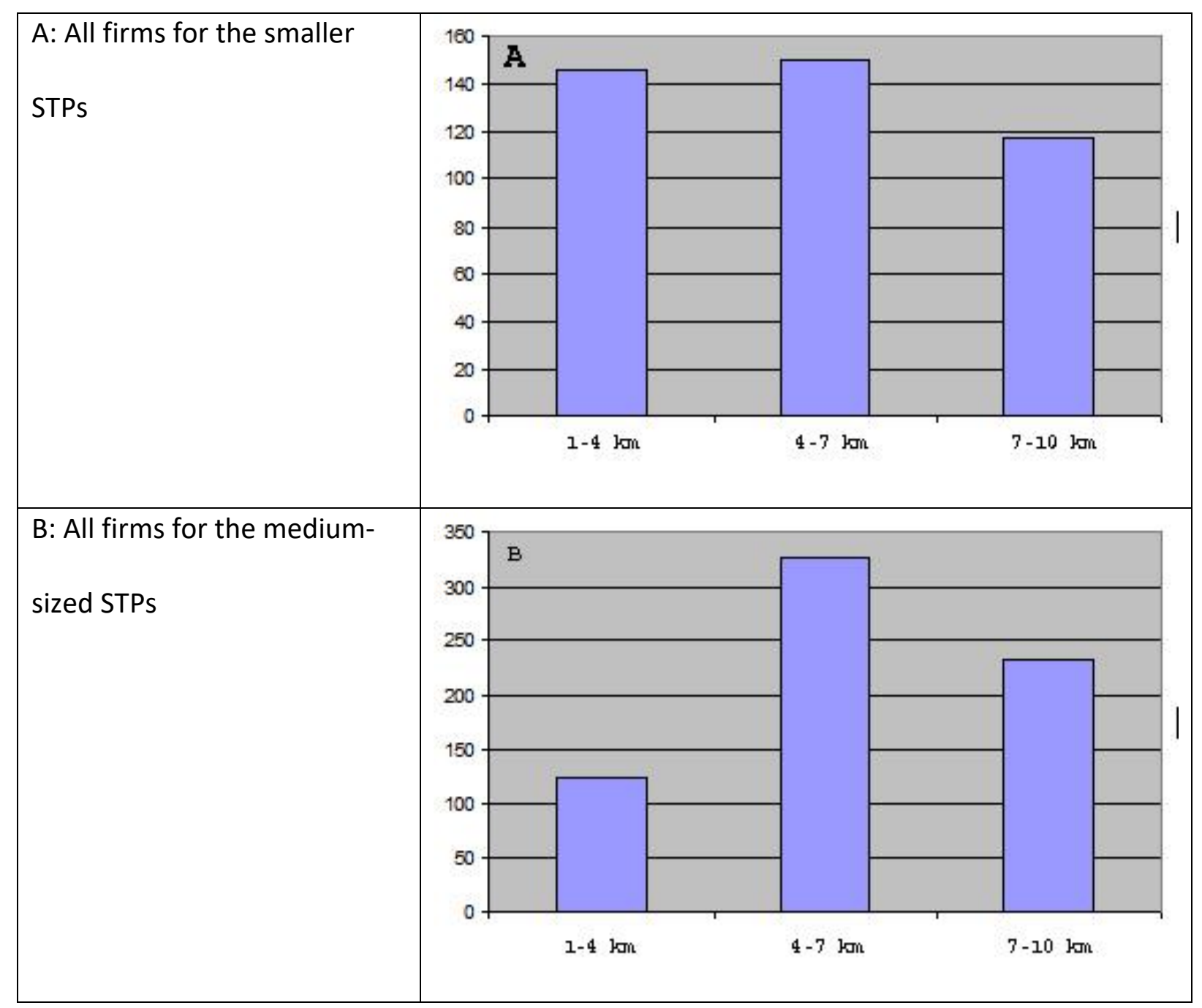

Figure 5. The distribution of off-cluster firms around STPs (originally fig 5 in Kussainov et al, 2020) 
Independently of the developmental stage of the STPs, and independently of specialization, off-cluster firms were predominant in the $4-7 \mathrm{~km}$ zone. Results may indicate that initially off-cluster firms are close, but with time and expansion, and with the help of new communications and other technologies, off-cluster firms are able to move away from the STP centre to more attractive locales. Nonetheless off-cluster firms still remain within relatively easy informational and travelling distance of the local STP (Kussainov et al, 2020) and are still within easy reach to participate in "local buzz" events etc.

Previous studies postulate that geographical proximity is linked to the efficacy of external networks, albeit only weakly (Crescanzia et al, 2016). The concept that firms may be able to move away from well-established STPs by using IT and network technologies results in them being able to enjoy an increased choice in finding premises that are more suitable. This idea is supported by the work of Nikiforou et al (2020) who found that in open markets as in the cases presented here - technological networks are equally as beneficial as physical associations.

The picture emerging from the data is that a communication factor, most probably IT/Internet and telephony/messaging, as indicated by Howells \& Bessant (2012), allows offcluster firms to diffuse outward to a distance of between 4 and $7 \mathrm{~km}$.

A further question is; is this trend universal? Tacit knowledge moves through formal and informal channels and is mostly beneficial for product innovation, while codified knowledge contributes to process innovation (Casanueva et al., 2013; Eisingerich et al., 2010). Will \& Mellor (2019) using large panel data sets, showed that product innovation (which may be most applicable to STPs) is more widespread in well-developed countries, with less well-developed countries tending towards process innovation, implying that significant differences may well be found in the activities of STPs between regions. In either 
case, government subsidies at firm level had no effect on innovation outputs (Will \& Mellor, 2019).

\section{Future directions}

There is immense scope for improvement; three areas ripe for investigation are described below.

(1) Baseline density of appropriate firms:

Innovations drive economic and social progress, yet we don't understand how companies and STPs can best develop, implement and spread useful innovations in a successful way (and this includes avoiding unsuitable innovations). It is unknown how many SMEs are needed per geographical area (and does this differ between particular industrial sectors?) to act as a base for an STP start up. These metrics need to be identified if planners want to identify where STPs may best succeed and is essential for the benefit of the taxpayer, local and central government planners. Firms choose to be within a cluster or not, so it should be clear to the large numbers of innovative technology entrepreneurs who may intend to inhabit the clusters, what "moving in" means for them in quantifiable terms, rather than any rosy perspectives presented by CIs needing to cover rent bills. Possible approaches could be based on Prisoners Dilemma or other Games Theory methods.

(2) Competition and distance between STPs:

In a world of political and economic turmoil, many regions, fearing downturn, want to stimulate innovation by founding more STPs etc, but this may simply lead to an overcrowded landscape, disappointing failures and even more scarce resources wasted. There is a lack of basic metrics like how close STPs can be to each other and if this varies with industrial sectors. To avoid "lock-in" with old technology, STPs 
need a regular influx of innovative firms with new ideas, yet it is unknown how they large and small - compete with each other for these firms in an eco-economical landscape, as well as how large is the minimum catchment needed and what churn rate amongst inhabitants is excessive.

(3) Triggers for changing strategic approach:

Most STPs fail to grow, implying that they are situated where there are too few firms in the local environment that have suitable innovations that need fostering in a STP; perhaps client firms have chosen other STPs or perhaps that Park has chosen clients with unsuitable innovations. If new STPs can attract sufficient firms with "good" innovations that are aligned and synergistic, then a "tipping point" will be reached where the STP will need to adjust its structure for more growth. Clearly there is much more work to be done regarding the developmental stages of STPs and it would be interesting to use panel data to investigate the relative importance of social expenditure, R\&D expenditure etc on innovation output comparing small STPs with those of modest size and with fully mature examples. A related aspect involves "top down" STPs and it would be useful if metrics like innovation input/output could be developed to distinguish between the more innovation-driven high-tech STPs and other, more general, business-hosting “clusters".

\section{Conclusion}

The adoption of two new concepts that allow the use of powerful econometric tools including Structural Equation Modelling (SEM) and Monte Carlo techniques, as well as mapping tools using Geographic Information Systems (GIS) and the use of both panel data and Big Data, have together given us powerful new insights into topics that are important for regional development. Furthermore, the research showcases the power of computer modelling and Big Data in bringing fresh approaches to previously intractable problems, and this, in turn, may 
bring significant benefits for economics and business studies, as well as for management and organization science.

The aim is to contribute towards a "road map" to help STP decision-making; some valuable principles have been elucidated and explained, but there is still a long way to go in this rapidly evolving area.

\section{References}

Albahari, A., Barge-Gil, A., Pérez-Canto, S. and Modrego, A. (2018). The influence of science and technology park characteristics on firms' innovation results. Papers in regional science, Vol. 97 No.2, pp.253-279.

Al-kfairy, M., Khaddaj, S. and Mellor, R. B. (2018). A longitudinal study of corporate benefits accrued by firms inhabiting a mature science park. In: Proceeding of the 19th European Conference on Knowledge Management. University of Padua, Italy. 6-7 September 2018. Vol. 1, pp76-84.

Al-kfairy, M., Khaddaj, S. and Mellor, R. B. (2019a). Computer modelling reveals the optimal development for the organisational structure of business clusters. International Journal of Knowledge-Based Development, Vol 10, No 3, pp 249-275

Al-kfairy, M., Khaddaj, S. and Mellor, R. B. (2019b). Computer modelling and identification of factors important for the success of business clusters. International Journal of Knowledge-Based Development, Vol 10, No 4, pp $384-405$

Al-kfairy, M., Khaddaj, S. and Mellor, R. B. (2020). Evaluating the effect of organizational architecture in developing science and technology parks under differing innovation environments. Simulation Modelling Practice and Theory, Vol 100, 102036.

Bathelt, H., Malmberg, A. and Maskell, P. (2004). Clusters and knowledge: local buzz, global pipelines and the process of knowledge creation. Progress in Human Geography, Vol. 28 No.1, pp. 31-56.

Bencke, F.F., Dorion, E.C.H., Prodanov, C.C. and Olea, P.M. (2019): Community leadership and the Triple Helix model as determinants of the constitution of science parks, a Brazilian experience. Benchmarking: An International Journal, Vol. 27 No. 1, pp. 2140.

Casanueva, C., Castro, I. and Galan, J.L. (2013). Informational networks and innovation in mature industrial clusters, Journal of Business Research, Vol. 66 No. 5, pp. 603 - 613. 
Charlot, S., Crescenzi, R. and Musoles, A. (2015). Econometric modelling of the regional knowledge production function in Europe. Journal of Economic Geography 151227 1259.

Delgado, M., Porter, M.E. and Stern, S. (2010). Clusters and entrepreneurship, Journal of Economic Geography, Vol. 10 No. 4, pp. 495-518.

Diez-Vial, I. and Fernández-Olmos, M. (2017). The effect of science and technology parks on a firm's performance: a dynamic approach over time. Journal of Evolutionary Economics, Vol. 27 No.3, pp. 413-434.

Díez-Vial, I and Montoro-Sánchez, A. (2016). How knowledge links with universities may foster innovation: The case of a science park. Technovation, Vol. 50, pp 41-52

Eisingerich, A.B., Bell, S.J. and Tracey, P. (2010). How can clusters sustain performance? The role of network strength, network openness, and environmental uncertainty. Research Policy, Vol. 39 No. 2, pp. 239-253.

Gower, S.M. and Harris, F.C. (1994): Science Parks in the UK: regional regenerators or just another form of property development? Property Management, Vol. 12 No. 4, pp. 2433.

Gower, S.M., Harris, F.C. and Cooper, P.A. (1996): Assessing the management of science parks in the UK. Property Management, Vol. 14 No. 1, pp. 30-38.

Guadix, J., Carrillo-Castrillo, J., Onieva, L. and Navascués, J. (2016). Success variables in science and technology parks. Journal of Business Research, Vol 69 No. 11, pp. 48704875 .

Hansson, F. (2007): Science parks as knowledge organizations - the "ba" in action? European Journal of Innovation Management, Vol. 10 No. 3, pp. 348-366.

Henriques, I.C., Sobreiro, V.A. and Kimura, H. (2018). Science and technology park: Future challenges, Technology in Society, Vol 53, pp.144-160.

Hobbs, K., Link, A. and Scott, J. (2017). Science and technology parks: an annotated and analytical literature review. The Journal of Technology Transfer, Vol.42 No.4, pp. 957-976.

Howells, J. and Bessant, J. (2012). The role of technology in shaping and overcoming space. Journal of Economic Geography vol 12, pp 929-942.

IASP (2020) Innovation ecosystems worldwide. [available at: http://www.iasp.ws/ Accessed 1 September 2020]. 
Johnston, A. (2019). The roles of universities in knowledge-based urban development: A critical review. International journal of knowledge-based development. International Journal of Knowledge-Based Development, Vol 10 No 3, pp.213 - 231

Johnston, A. (2020). Open innovation and the formation of university-industry links in the food manufacturing and technology sector: evidence from the UK. European Journal of Innovation Management. [available at http://doi.org/10.1108/EJIM-06-2019-0163 accessed 2 September 2020].

Johnston, A and Huggins, R (2018): Partner selection and university-industry linkages: Assessing small firms' initial perceptions of the credibility of their partners. Technovation, Vol 78, pp 15-26

Kelly, T.J.C. and Firestone, R.S. (2016). How tech hubs are helping to drive economic growth in Africa. World Development Report background papers. Washington, D.C.: World Bank Group.

Kussainov, A., Kumar, Y., Pflugel, E. and Mellor, R. B. (2020). Innovation still does not travel well, but is improving: The distribution of off-cluster firms around four UK science parks. Proceedings of TAKE 2020: Theory \& Applications in the Knowledge Economy, July 1-3, 2020, Stuttgart, Germany. [Available on ssrn.com/abstract=3544917 accessed 13 May 2020]

Lecluyse, L., Knockaert, M. and Spithoven, A. (2019). The contribution of science parks: a literature review and future research agenda. The Journal of Technology Transfer, Vol. 44, No 2, pp.559- 595.

Maskell, P. (2001) Towards a knowledge-based theory of the geographical cluster, Industrial and Corporate Change, Vol 10 No 4, pp. 921-943.

McCann, B.T. and Folta, T.B. (2011) Performance differentials within geographic clusters. Journal of Business Venturing Vol. 26 No 1, pp. 104-123.

Mellor, R. B. (2014a). Knowledge valley theory. International Journal of Knowledge-Based Development, Vol. 5, No. 1, pp. 5 - 16.

Mellor, R. B. (2014b). The use of knowledge assets: modelling the potential effect of adding innovators to low-innovation and high-innovation SMEs. International Journal of Knowledge-Based Development, Vol. 5, No.4, pp. 367 - 380.

Mellor, R. B. (2015a). Computer-modelling the innovation-based theory of the firm. In: 16th European Conference on Knowledge Management ECKM 2015; 3 - 4 Sep 2015, Udine, Italy pp 532 - 538. [Available on ssrn.com/abstract=3534736 accessed 13 May 2020] 
Mellor, R. B. (2015b). Modelling the value of external networks for kvisitednowledge realisation, innovation, organisational development and efficiency in SMEs. International Journal of Knowledge-Based Development, Vol. 6, No. 1, pp. 3 - 14.

Mellor, R. B. (2016) Computer modelling the costs of management control in the development of knowledge-based SMEs. International Journal of Knowledge-Based Development, Vol. 7, No 4, pp 378 - 388

Mellor, R. B. (2018). Big Data modelling the knowledge economy. International Journal of Knowledge-Based Development, Vol. 9, No 3, pp 206-220.

Mellor, R.B. (2019). Entrepreneurship. In; Mellor, R.B. Management for scientists. Bingley, Emerald

Mellor, R.B. (2020). Knowledge-sharing in the development of Science and Technology Parks. Proceedings of TAKE 2020: Theory \& Applications in the Knowledge Economy, July 1-3, 2020, Stuttgart, Germany. [Available on DOI.org/10.13140/RG.2.2.33356.23687 accessed 13 May 2020]

Nikiforou, A. Lioukas, S and Voudouris, I (2020). Network structure and firm-level entrepreneurial behaviour: The role of market and technological knowledge networks. Journal of Business Research, 106, 129-138

Porter, M. E. (1990): The competitive advantage of nations. New York: Free Press.

Pugh, R., MacKenzie, N.G. and Jones-Evans, D. (2018). From 'techniums' to 'emptiums': the failure of a flagship innovation policy in Wales. Regional Studies, Vol 52, No.7, pp. 1009-1020.

Rodríguez-Pose, A. and Comptour, F. (2012). Do clusters generate greater innovation and growth? An analysis of European regions. The Professional Geographer, Vol 64, No 2, pp 211-231,

Rodríguez-Pose, A and Crescenzi, R. (2008). Research and development, spillovers, innovation systems, and the genesis of regional growth in Europe. Regional Studies, Vol 42 No 1, pp 51-67

Rowe, D. (2014). Setting up, managing and evaluating EU science and technology parks. Luxembourg: EUR-OP. [available at https://ec.europa.eu/regional_policy/sources/docgener/studies/pdf/stp_report_en.pdf. accessed October 2019].

Skokan, K., Poledníková, E. and Stanícková, M. (2012). Establishment and growth of business clusters with public aid. Journal of Competitiveness, Vol.4 No.3. 
Sternberg, R. (2014). Success factors of university-spin-offs: Regional government support programs versus regional environment. Technovation, Vol. 34, No. 3, pp. 137-148.

Stigliz, J.E. and Greenwald, B.C. (2014). Creating a Learning Society. Columbia University Press. ISBN: 9780231525541

Sureephong, P., Chakpitak, N., Ouzrout, Y., Neubert, G. and Bouras, A. (2007). Knowledge management system architecture for the industry cluster. In 2007 IEEE International Conference on Industrial Engineering and Engineering Management (pp. 1970-1974). IEEE.

Vásquez-Urriago, Á. R., Barge-Gil, A. and Modrego Rico, A. (2016). Science and Technology Parks and cooperation for innovation: Empirical evidence from Spain. Research Policy, Vol. 45 No. 1, pp. 137-147.

Wadhwa, V. (2013). Silicon Valley can't be copied. Technology Review, Vol 116, No.5, pp. 87-88.

Will, M. G., Al-Kfairy, M. and Mellor, R. B. (2019). How organizational structure transforms risky innovations into performance - a computer simulation. Simulation Modelling Practice and Theory, Vol. 94, pp 264 - 28

Will, M.G. and Mellor, R.B. (2019). Differences in creating product innovations versus process innovations across European industries. International Journal of Innovation and Regional Development. Vol 9, No 1, pp 59 - 84.

Zhang, G., Duan, H. and Zhou, J. (2017). Network stability, connectivity and innovation output. Technological Forecasting and Social Change, Vol 114, pp 339-349.

\section{Appendix: Note on the methodology applied to generate Figure 2 and Figure 3}

Figure two and three were generated by applying the following equations:

\section{For Figure two:}

$\mathrm{b}=\sum_{\mathrm{i}=1}^{\mathrm{n}} \operatorname{Innov}_{\mathrm{i}}$

$\mathrm{b}$ is the net total innovation, Innov $\mathrm{v}_{\mathrm{i}}$ is the incoming innovation project value for firm (i) 


$$
\operatorname{Innov}_{i}=I_{i}-C_{i}
$$

Where $\mathrm{I}_{i}$ is the innovation cash value (benefit generated by implementing a specific innovation project) and $C_{i}$ is the cost of implementing that innovation. Innovi was generated from a uniform distribution with a Monetary Unit (MU) range between -1,000 and 1,000, then applying Monte-Carlo simulations using MatLab software.

\section{For Figure three:}

$b=\left\{\begin{array}{c}\sum_{i=1}^{n} \text { Innov }_{i}-3 \times T C_{i}, i f\left(\mu\left(q_{c}, q_{f, i}, q_{f, i}\right)>0.75 \text { and }\left(\text { Innov }_{i}-3 \times T C_{i}\right)>0\right) \text { or }\left(\left(d_{i}>0.5\right) \text { and }\left(d_{j}>0.5\right) \text { and }\left(C I_{i}>0.5\right)\right) \\ b-3 \times T C_{i}, i f\left(\mu\left(q_{c}, q_{f, i}, q_{f, i}\right)>0.75 \text { and }\left(\text { innov }_{i}-3 \times T C_{i}\right)<0\right) \text { or }\left(\left(d_{i}<0.5\right) \text { or }\left(d_{j}>0.5\right) \text { or }\left(C I_{i}<0.5\right)\right)\end{array}\right.$

In this case, the equation takes into account the quality of decision-making shown by the managers of the on-cluster firms involved, which were generated randomly from uniform distribution and using the mean value of the quality of all managers (CI and on-cluster firms managers); if the mean value is greater than 0.75 , then the managers will mostly make the right decision (i.e. accept good innovations and reject bad innovations) while simultaneously controlling for the transaction costs generated $\left(T C_{i},\right)$ which was derived from a uniform distibution between 0 and 100 MU. 